\title{
Effect of Submillimeter Variation in Plunge Depth on Microstructure and Mechanical Properties of FSLW 2A12 Aluminum Alloy Joints
}

\author{
Dan Chen ${ }^{1,2} \cdot$ Jinglong $\mathrm{Li}^{1,2} \cdot$ Huaxia Zhao ${ }^{3} \cdot{\text { Zhejun } \operatorname{Tan}^{2}}^{2}$ Jiangtao Xiong ${ }^{1}$
}

Received: 6 April 2019 / Revised: 19 August 2019 / Published online: 17 December 2019

(C) The Chinese Society for Metals (CSM) and Springer-Verlag GmbH Germany, part of Springer Nature 2019

\begin{abstract}
Friction stir lap welding was conducted on $2 \mathrm{~mm}+2 \mathrm{~mm}$ sheets of aluminum alloy 2A12-T4. The plunge depth (PLD) was designed as $2.45-2.58 \mathrm{~mm}$, which was varied in submillimeters as $2.45,2.50,2.53,2.55$, and $2.58 \mathrm{~mm}$, and the axial force was recorded in the welding process. The results show that the PLD fluctuation in submillimeters causes significant variation in the axial force and affects the voids (i.e., Void I and Void II), hook, and effective sheet thickness (EST), among which Void I is the main factor that affects the EST. The fracture load-PLD function in the tensile shear test of the joints follows the rule of the EST-PLD function. An optimized PLD is approximately $2.55 \mathrm{~mm}$, at which the EST reaches $1.71 \mathrm{~mm}$, corresponding to a peak fracture load of $11.03 \mathrm{kN}$. Thus, a PLD of $2.55 \mathrm{~mm}$ is suggested with a tolerance of $0.02 \mathrm{~mm}$, corresponding to a fracture load of $9.6-11.0 \mathrm{kN}$, i.e., within a fluctuation of $12 \%$.
\end{abstract}

Keywords Submillimeter $\cdot$ Plunge depth $\cdot$ Mechanical properties $\cdot$ Friction stir lap welding

\section{Introduction}

Friction stir welding (FSW) is a solid-state welding technique, especially in joining aluminum alloys, and it has been widely applied in the manufacturing of aircraft, rail transport, and so on [1-3]. FSW can form many joint types, including butt-, lap-, T-, and corner-type joints. Friction stir lap welding (FSLW) has been developed for lap-type joining.

As with FSW, the FSLW parameters commonly include pin geometry and such welding parameters as rotation speed, traverse speed, and plunge depth (PLD). In both FSW and FSLW, after the plates are rigidly fixed, the tool rotates and presses down to the preset PLD, and then it traverses horizontally, in which the rotation speed, welding speed, and

Available online at http://link.springer.com/journal/40195.

Jinglong Li

lijinglg@nwpu.edu.cn

1 State Key Laboratory of Solidification Processing, Northwestern Polytechnical University, Xi'an 710072, China

2 Shaanxi Key Laboratory of Friction Welding Technologies, Northwestern Polytechnical University, Xi' an 710072, China

3 AVIC Manufacture Technology Institute, Beijing 100024, China
PLD are supposed to be constant throughout the welding cycle [4-6].

A slight fluctuation of PLD can occur owing to plate thickness tolerance and welding thermal deformation, and this could cause the microstructure and mechanical properties of the joint to vary from location to location. The instability of the joint mechanical properties has become an obstacle in FSLW application.

Studies on PLD have been reported [7-10]. It has been suggested that the PLD should be larger than the thickness of the upper plate so that the pin can penetrate into the lower plate. Kim et al. [7] reported that insufficient PLD can lead to void defects in the weld. When the PLD was varied at an interval of 0.3-0.5 mm, the PLD had an apparent effect on the microstructure and defects of the joints [5, 9, 10]. Based on the above, the defects, i.e., void, hook, and cold lap, were characterized, and welding parameters were optimized to suppress those defects and promote the mechanical properties [11-19].

Few studies have been reported on PLD that focused on its adjustment at a submillimeter scale to study the stability of the joint mechanical properties in FSLW, because it is difficult to measure the PLD in real time during the welding process. An applicable way was found in robotic FSW, which was set in force control mode. To compensate for the compliant nature of the robot, the force was monitored and fed back to ensure 
a steady PLD [20]. This method can be utilized by monitoring the axial force as a referable parameter to characterize the PLD.

In this study, FSLW was conducted on 2A12-T4 aluminum alloy. The PLD was designed as $2.45-2.58 \mathrm{~mm}$, varied in submillimeters as $2.45,2.50,2.53,2.55$, and $2.58 \mathrm{~mm}$, to simulate the PLD fluctuation in the welding production. The axial force was recorded to characterize the PLD in the welding process. The joint microstructure was observed, and the mechanical properties were tested, on which the effect of PLD fluctuation was studied. The result provides a ready reference for the stability control of the joint mechanical properties in industrial production.

\section{Experimental Procedure}

The base metal (BM) was commercially available aluminum alloy sheet 2A12-T4 (solution treated and naturally aged) covered by a $100-\mu \mathrm{m}$-thick Alclad. The sheet thickness was $2 \mathrm{~mm}$. Table 1 lists the nominal chemical composition of the BM, which belongs to the Al-Cu system alloy with copper as the main alloying element.

The FSLW experiment was conducted by a four-axis linkage FSW machine (CFSW E158, China). The tool was designed with a shoulder $\phi 10 \mathrm{~mm}$ in diameter and a tapered pin $2.40 \mathrm{~mm}$ in length, and it was optimized based on previous research $[3,10]$. The sheets were stacked in lap joint mode and were welded at a constant rotation speed of $1000 \mathrm{rpm}$ and a welding speed of $200 \mathrm{~mm} / \mathrm{min}$ with a tilt angle set as $2.5^{\circ}$. The PLDs were set as $2.45,2.50,2.53,2.55$, and $2.58 \mathrm{~mm}$. On the spindle screw of the tool, a tension/compression sensor (AVIC Zemic B12G-G2, China) was installed to record the welding axial force. To minimize the error, before welding, the worktable was horizontally aligned by a dial gauge. To ensure the preset PLD at the beginning of welding, a tool setting program was performed, i.e., when the axial force reached $2 \mathrm{kN}$, the numerical control system recognized that the pin had come into contact with the sheet. Thus, this height was recorded as the zero point of the $Z$-axis, from which the pin moved down to a preset PLD value. Thereafter, the pin traversed (parallel to the rolling direction), and the welding process started.

After welding, the joints were cut into samples for observation of the microstructures and testing of the mechanical properties. Keller's reagent was used for sample etching. By using a Vickers sclerometer (LECO HV-1000, America) with a load of $200 \mathrm{~g}$ and dwell time of $10 \mathrm{~s}$, the microhardness was measured on a cross section of the joint along the half-thickness line of the upper sheet with a testing step of $0.25 \mathrm{~mm}$. Figure 1 shows the structure of the tensile shear test samples, which were prepared according to China National Standard GB/T 228.1-2010. The tensile shear tests were carried out by an electronic universal testing machine (Zwick Allroundline Z100, Germany) at a loading speed of $1.5 \mathrm{~mm} / \mathrm{min}$. According to Liu et al. [4], the lap joint can be welded in two modes-Types A and B-in which Type A configures the retreating side (RS) on the edge of the upper sheet and leaves the advancing side (AS) inside, whereas Type B is reversed. In this study, Type A was adopted, as shown in Fig. 1.

The cross section of the joint and fracture morphology of the tested sample was analyzed by an optical microscope (Olympus PMG3, Japan) and scanning electron microscope (Zeiss Supra 55 Sapphire, Germany).

\section{Results and Discussion}

\subsection{Axial Force Evolution}

Figure 2 shows the axial force evolutions in the welding process, and Fig. 2a classifies the welding cycle into two stages: the plunge stage and steady stage (walking stage). Figure $2 b$ shows the axial forces at different PLDs. It was found that the axial force at the steady stage does not remain constant. It fluctuated significantly after the PLD was set as and over $2.53 \mathrm{~mm}$.

The axial force-PLD relationship has been studied extensively [20-22], and the power law function was written, within a certain range, as

$F=K_{\mathrm{p}} d^{\gamma}$

where $F$ is the axial force, $d$ is the PLD, $K_{\mathrm{p}}$ and $\gamma$ are constants related to the welding parameters, i.e., rotation speed

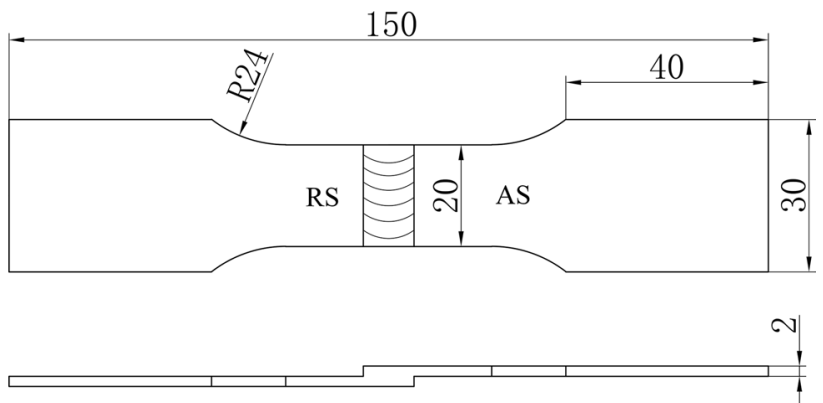

Fig. 1 Dimensions and configuration of the tensile shear samples
Table 1 Nominal chemical composition of 2A12-T4 Al alloy (wt\%)

\begin{tabular}{lllllllll}
\hline $\mathrm{Cu}$ & $\mathrm{Si}$ & $\mathrm{Fe}$ & $\mathrm{Mn}$ & $\mathrm{Mg}$ & $\mathrm{Ni}$ & $\mathrm{Zn}$ & $\mathrm{Ti}$ & $\mathrm{Al}$ \\
\hline $3.8-4.9$ & 0.50 & 0.50 & $0.30-0.9$ & $1.2-1.8$ & 0.10 & 0.30 & 0.15 & Bal. \\
\hline
\end{tabular}



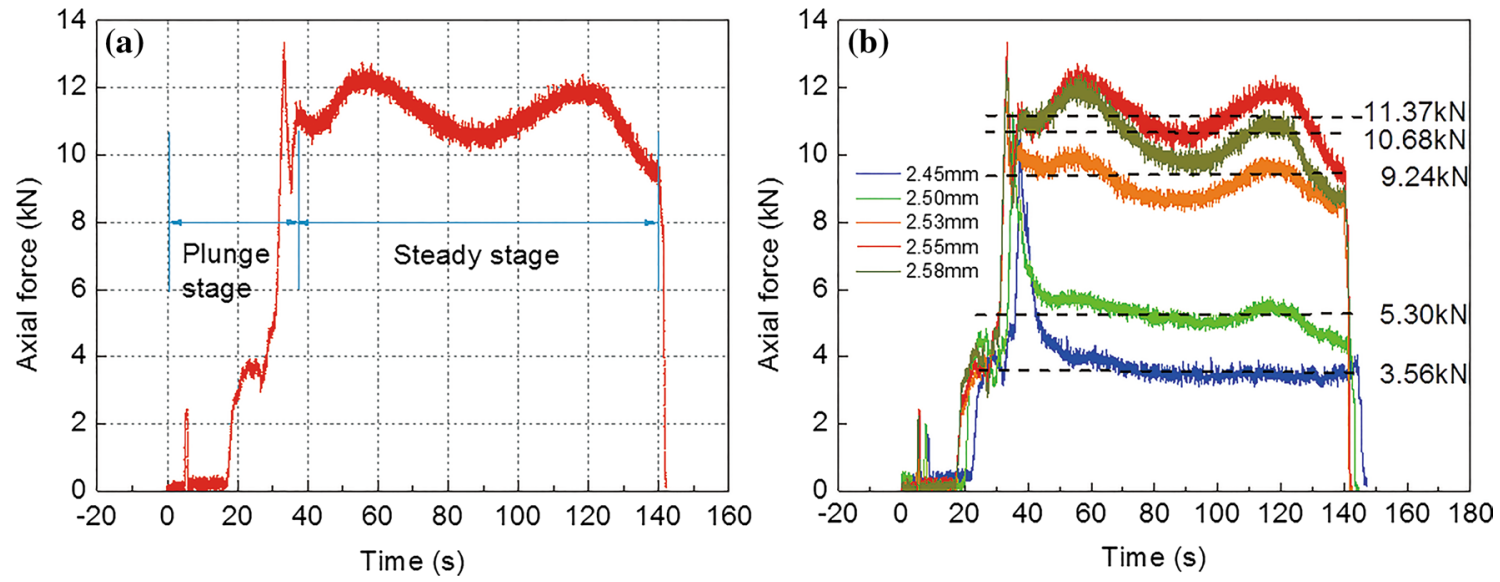

Fig. 2 Axial force evolutions showing a welding stage classification in a welding cycle, $\mathbf{b}$ the effect of the PLD

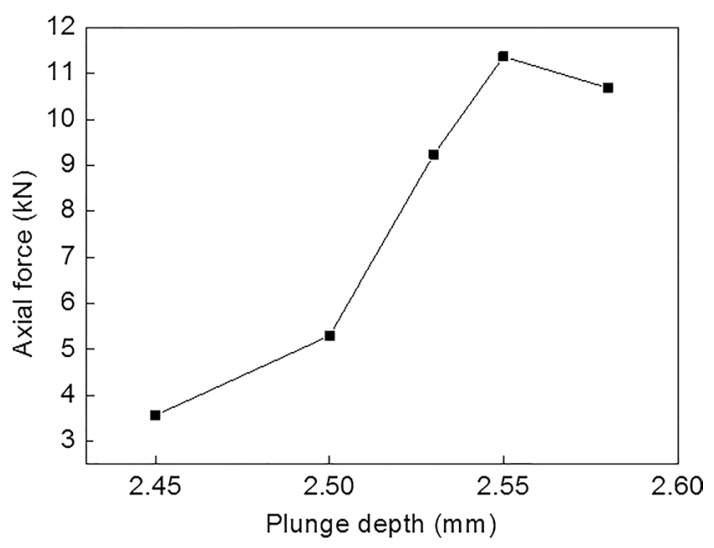

Fig. 3 Correlation between the axial force and the PLD

and welding speed. By the regression of the welding parameters, $K_{\mathrm{p}}$ and $\gamma$ could be derived, and the PLD could be determined by the axial force. This function could be later integrated into welding control.

The axial force was collected corresponding to the PLD and averaged by the least-squares method. Figure 3 shows the correlation between the axial force and the PLD, which indicates the strong impact of the PLD on the axial force variation. As the PLD was increased from 2.45 to $2.55 \mathrm{~mm}$ by a step of $0.1 \mathrm{~mm}$ (i.e., submillimeters) or $4 \%$, the axial force rapidly increased from 3.56 to $11.37 \mathrm{kN}$ by a step of $70 \%$, which follows Eq. (1). Yet, the axial force did not follow Eq. (1) as the PLD was further increased to $2.58 \mathrm{~mm}$, but it ceased to increase (declined slightly). This phenomenon may be caused by the strong friction heat at high PLD, which softens the nugget zone (NZ) metal, and the axial force was consequently released to some extent.

\subsection{Joint Morphology Evolution}

Joint morphology examinations were conducted, in which the defects of hook, cold lap, and voids were focused on, because their geometries could significantly affect the mechanical properties of the joints. The sampling location was determined in accordance with the local axial force, which was stable and close to the average value. Thus, the corresponding PLD could be referred to as the featured variable.

Figure 4 shows the section morphologies of the joints welded at different PLDs. The joints show a common appearance, as in Fig. 4a, which includes the NZ, thermomechanically affected zone (TMAZ), and heat-affected zone. The NZ is further divided into the shoulder-influenced zone (SIZ) and the pin-influenced zone (PIZ). The hook on the AS bent slightly upward, whereas the cold lap on the RS bent upward and then extended downward into the NZ.

In FSLW, voids are normally found at two locations, as marked in Fig. 4a. Void I is formed on AS, at the intersection of SIZ and PIZ, whereas Void II is at the bottom of the PIZ. Void I is critical for reducing the effective sheet thickness (EST) of the joint to reduce the mechanical property. Both Void I and Void II were found at a PLD of $2.45 \mathrm{~mm}$, as shown in Fig. 4a, which were shrunk greatly at $2.50 \mathrm{~mm}$, as shown in Fig. 4b, and further disappeared when the PLD was set greater than $2.50 \mathrm{~mm}$, as shown in Fig. 4c-e. This phenomenon implies that, for safety, the PLD should be set higher than $2.50 \mathrm{~mm}$.

Hook and cold lap are typical phenomena in FSLW, and they can be further characterized by EST and effective lap width (ELW) [1, 3]. EST and ELW describe their effects on lap joint strength, in which EST corresponds to a tensile fracture mode and ELW to a shear fracture mode. The former was found later in tensile shear testing of the joints, which fractured on the AS. Thus, the EST was measured. The EST 


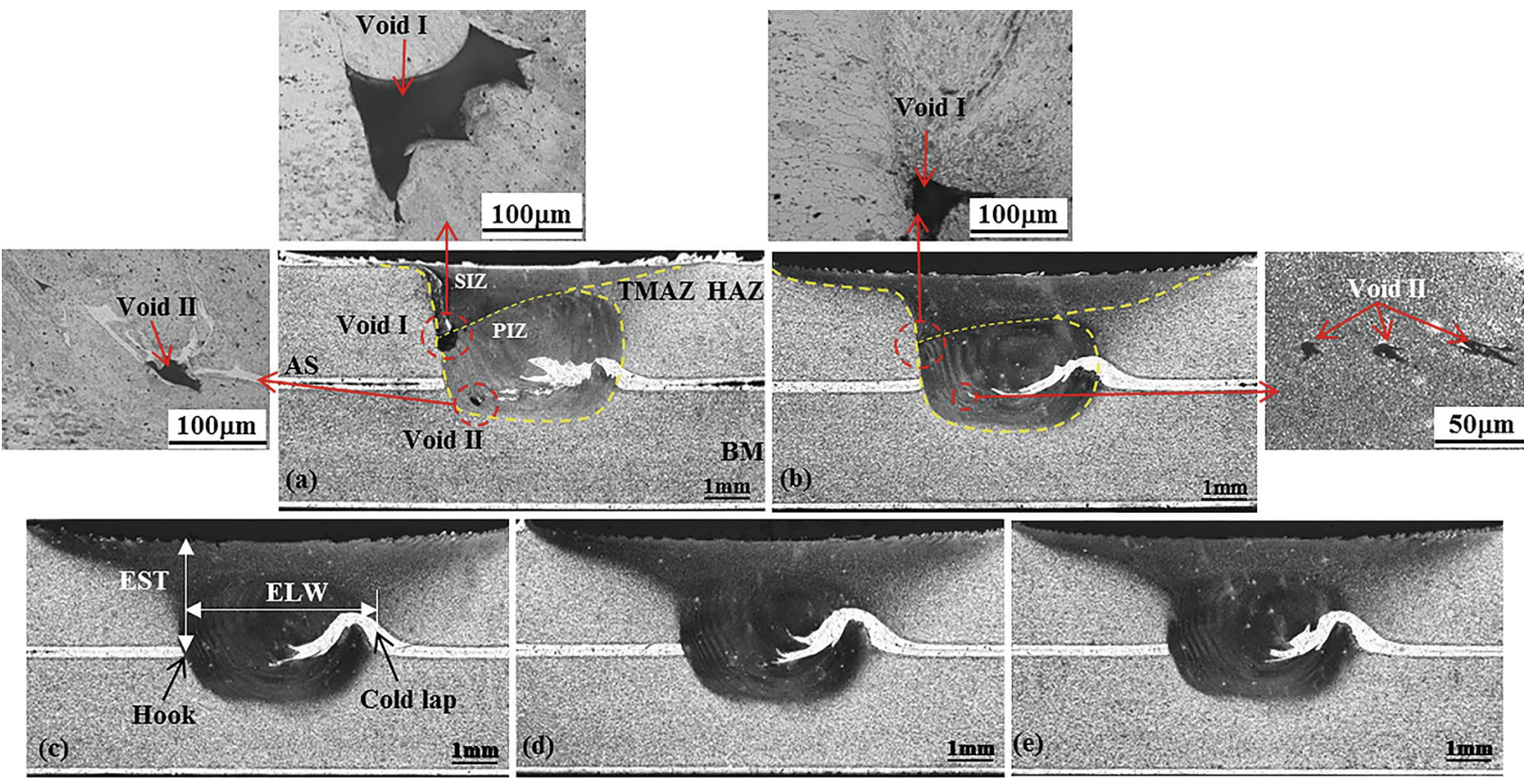

Fig. 4 Cross section morphologies of the joint welded at PLDs of a $2.45 \mathrm{~mm}, \mathbf{b} 2.50 \mathrm{~mm}, \mathbf{c} 2.53 \mathrm{~mm}, \mathbf{d} 2.55 \mathrm{~mm}$, e $2.58 \mathrm{~mm}$

on the AS is defined as the vertical distance between the hook tip and the top surface of the upper sheet, in which the height of Void I is excluded.

Figure 5 shows the hooks on the AS using different PLDs, which originate from the lap intersection and bend up slightly. Figure 6 shows the hook height and EST as functions of PLD. The hook height dropped down slightly in several tens of microns, i.e., a maximum of approximately $0.02 \mathrm{~mm}$, as the PLD was increased. This was totally suppressed when the PLD reached more than $2.53 \mathrm{~mm}$. However, the EST rose by approximately $0.2 \mathrm{~mm}$ as the PLD increased, which resulted mainly from the vanishing of Void I. This fact indicates that the PLD fluctuation in submillimeters mainly has an impact on the void size, which may substantially affect the mechanical properties of the joint, in which the hook height plays a

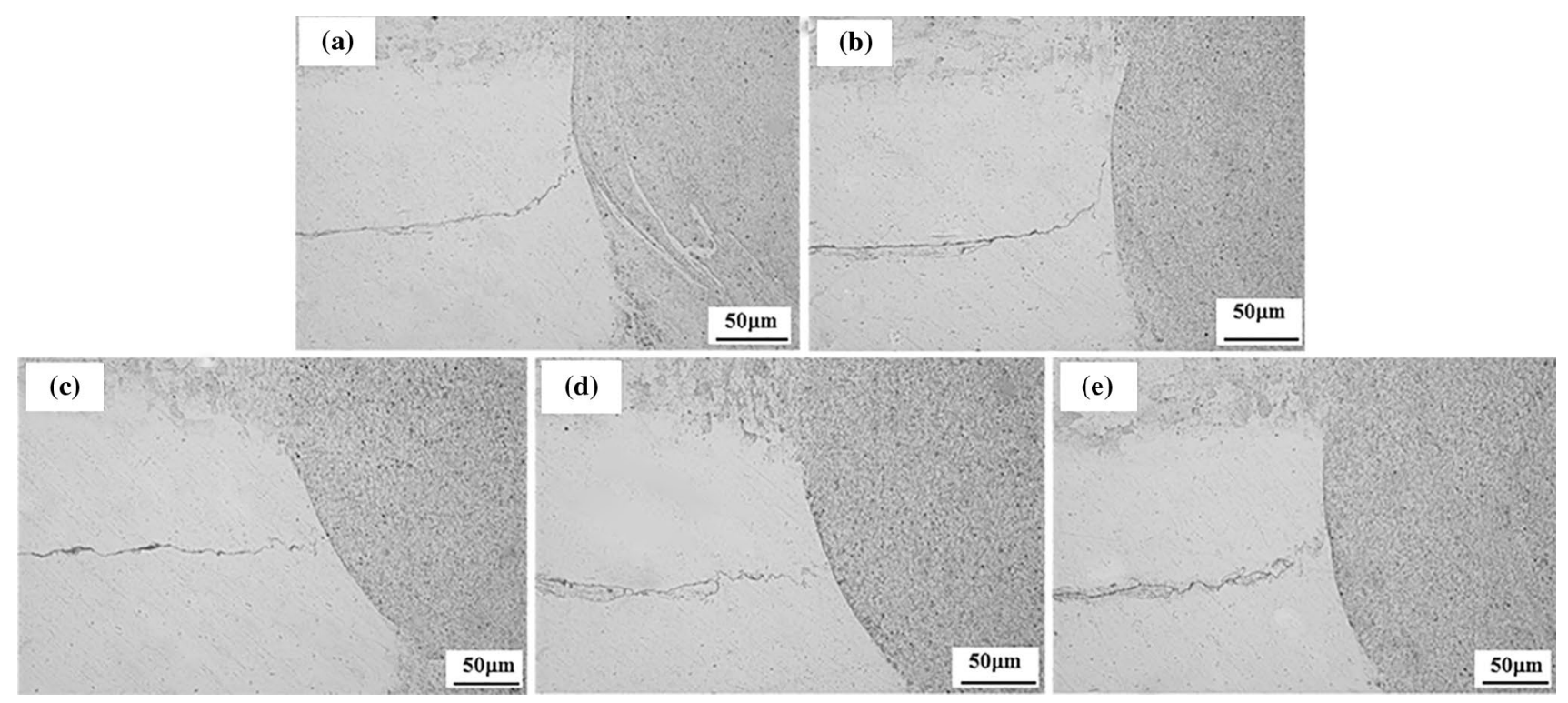

Fig. 5 Morphologies of the hook defects on the AS of the joint welded at PLDs of a $2.45 \mathrm{~mm}, \mathbf{b} 2.50 \mathrm{~mm}, \mathbf{c} 2.53 \mathrm{~mm}, \mathbf{d} 2.55 \mathrm{~mm}, \mathbf{e} 2.58 \mathrm{~mm}$ 


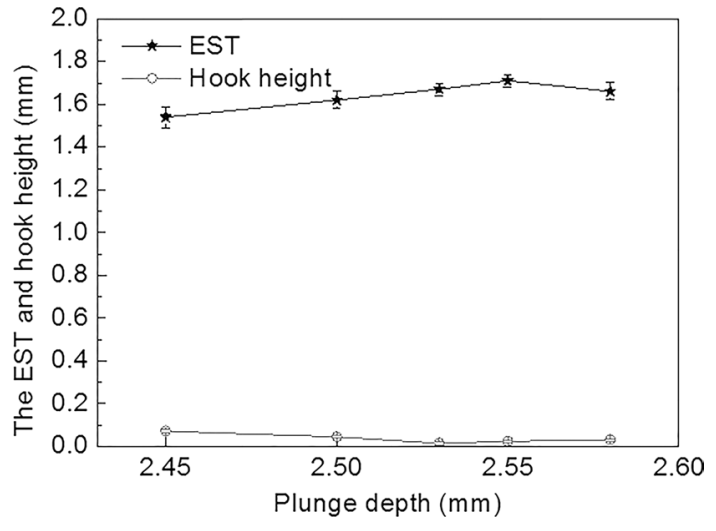

Fig. 6 Measurements of the heights of the hook and the EST as functions of the PLD

small role. It is noticeable, however, that the EST-PLD function follows the rule of the axial force-PLD function (Fig. 3), in which the axial force declined slightly after the PLD was raised more than $2.55 \mathrm{~mm}$, owing to, possibly, the same mechanism.

Figure 7 shows the microstructure of the TMAZ/NZ interfaces using different PLDs. The Alclad bulk suffered from an insufficient stirring effect, which was found in the NZ near the interface at a PLD of $2.45 \mathrm{~mm}$ and was suppressed with the increase in PLD. When the PLD was set as and over $2.53 \mathrm{~mm}$, the Alclad was redistributed and mixed well with $2 \mathrm{~A} 12$, as shown in Fig. $7 \mathrm{c}-\mathrm{e}$, which implies good bonding.

\subsection{Mechanical Properties of the Joints}

Figure 8 shows the mechanical properties of the joint. Figure $8 \mathrm{a}$ shows the microhardness distributions of the joint measured at different PLDs. These distributions are lower than the BM, indicating a softened NZ. However, the averaged hardness was derived as a function of PLD, as shown in Fig. 8b, and the averages of both the joint and NZ show the same trend with a peak value around HV 135 at a PLD of $2.53 \mathrm{~mm}$. This point (i.e., PLD $2.53 \mathrm{~mm}$, HV135) implies adequate friction heating and a long dwell time at high temperature [23], which enables the intermetallics, such as $\mathrm{Al}_{2} \mathrm{CuMg}$ [24], to precipitate.

Figure $8 \mathrm{c}$ shows the results of tensile shear tests. The fracture load rises along with the PLD and reaches the peak value of approximately $11.0 \mathrm{kN}$ at a PLD of $2.55 \mathrm{~mm}$. The fracture load-PLD function follows the EST-PLD function (Fig. 6). Further increase in the PLD causes a slight decline of the fracture load corresponding to the EST decline at a PLD of $2.58 \mathrm{~mm}$. When the PLD was increased from 2.45 to $2.55 \mathrm{~mm}$, i.e., $0.1 \mathrm{~mm}$, the fracture load rose from 3.5 to $11.0 \mathrm{kN}$. This fluctuation exceeds $65 \%$, which confirms the importance of the PLD control. A suggested PLD is $2.55 \mathrm{~mm}$ with a tolerance of $0.02 \mathrm{~mm}$, corresponding to a fracture load of $9.6-11.0 \mathrm{kN}$, i.e., within a fluctuation of $12 \%$.

Both joints at PLDs of 2.45 and $2.55 \mathrm{~mm}$ were examined for comparison, corresponding to the lowest and highest fracture loads, respectively. Figure 9 shows the fracture morphologies of the joint at a PLD of $2.45 \mathrm{~mm}$, in which

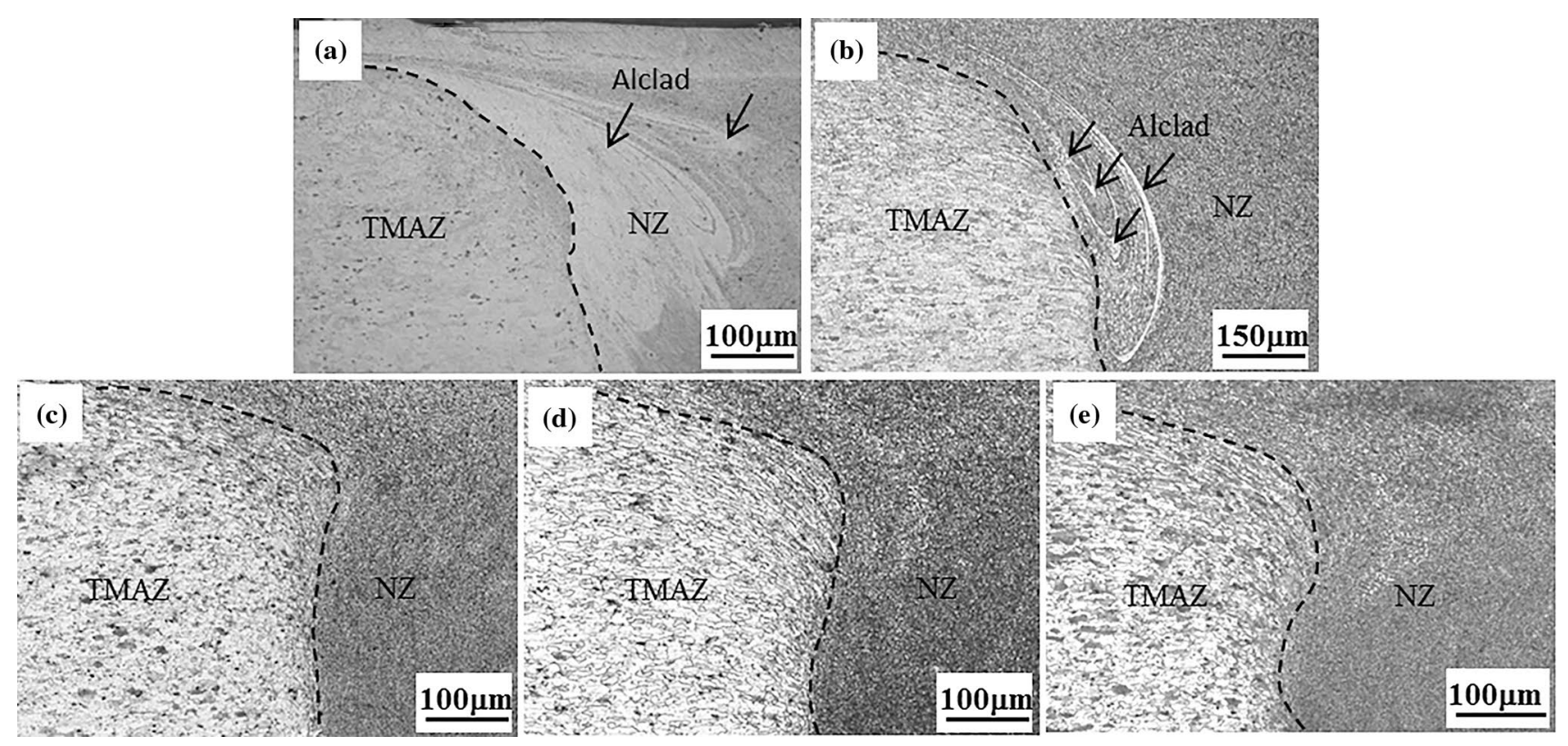

Fig. 7 Microstructures of the TMAZ/NZ interface on the AS of the joint welded at PLDs of a $2.45 \mathrm{~mm}, \mathbf{b} 2.50 \mathrm{~mm}, \mathbf{c} 2.53 \mathrm{~mm}, \mathbf{d} 2.55 \mathrm{~mm}$, e $2.58 \mathrm{~mm}$ 

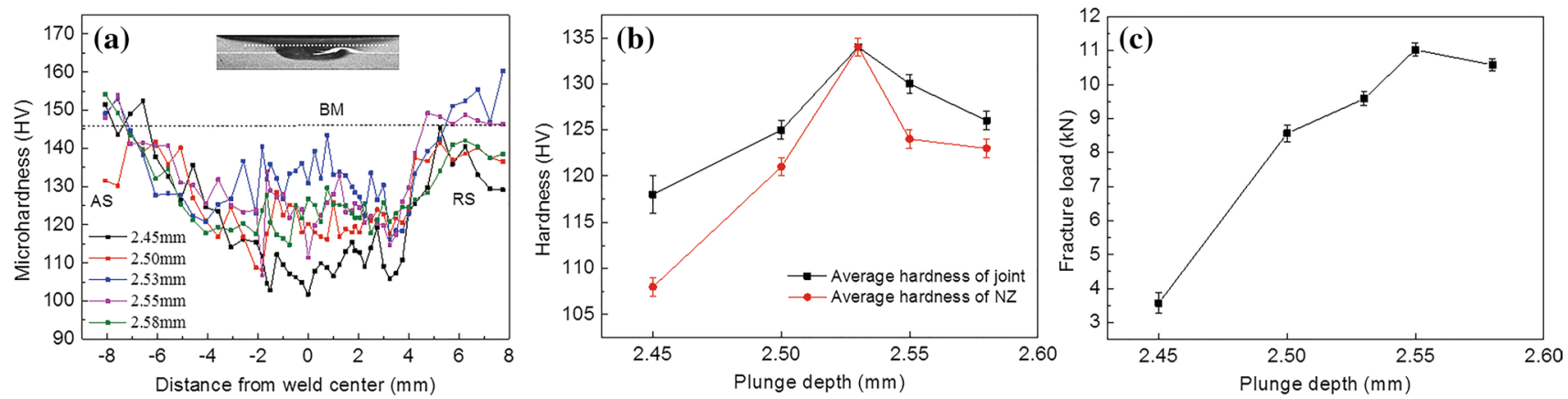

Fig. 8 Mechanical properties of the joints showing $\mathbf{a}$ the microhardness distributions, $\mathbf{b}$ the average hardness as a function of PLD, $\mathbf{c}$ the fracture load as a function of PLD

Void I was formed. Three regions were found on the fracture surface, denoted as A, B, and C. Regions A and C present a dimple structure, indicating a soft matrix, on which the dimple size (big and small) may result from the microstructure gradient caused by the temperature gradient vertically through the NZ [18]. Region B, corresponding to the location of Void I, shows a flat surface only with some scratches left by tools. In the tensile shear test, the crack initiates from the edge of Void I owing to stress concentrations and propagates up and down in two directions, which implies that the fracture load of the joint at low PLD is controlled by Void I formed on the AS.

Figure 10 shows the fracture morphologies of the joint at a PLD of $2.55 \mathrm{~mm}$, in which Void I has been eliminated, and good bonding has formed at the TMAZ/NZ interface owing to sufficient force and heat. The fracture surface mainly consists of fine deep dimples. In the tensile shear test, the crack initiates from the hook tip because of stress concentrations and then propagates along a $45^{\circ}$ direction to the loading direction (i.e., crossing the TMAZ and NZ), similar to bulk alloy.

\section{Conclusions}

FSLW was conducted on 2A12-T4 aluminum alloy sheets at a rotation speed of $1000 \mathrm{rpm}$ and welding speed of $200 \mathrm{~mm} / \mathrm{min}$. The PLD was designed as $2.45-2.58 \mathrm{~mm}$, varied by steps in submillimeters as $2.45,2.50,2.53,2.55$, and $2.58 \mathrm{~mm}$, and the axial force was recorded in the welding process. The effect of the PLD on the microstructure

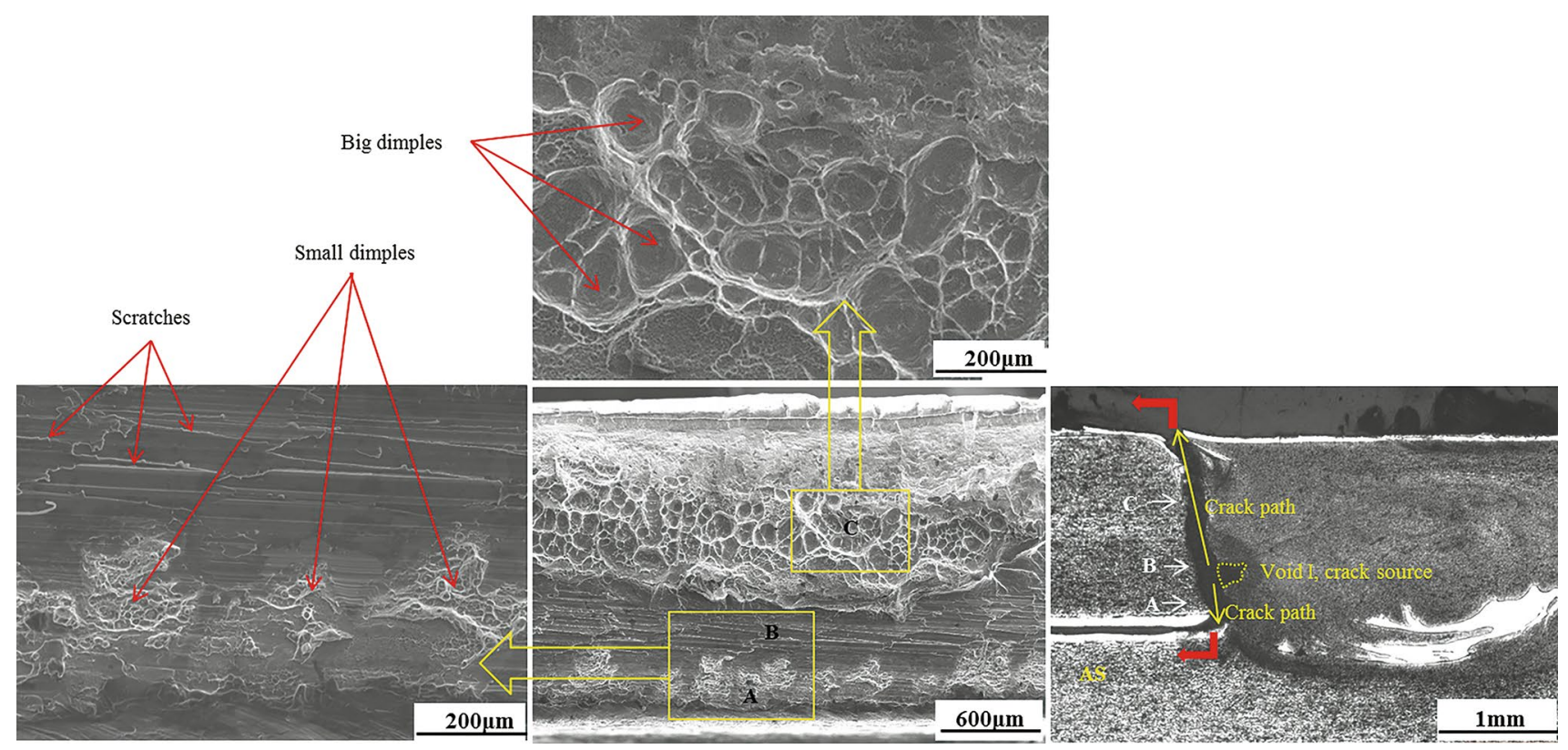

Fig. 9 Crack path and fracture morphology of the joint welded at a PLD of $2.45 \mathrm{~mm}$ 

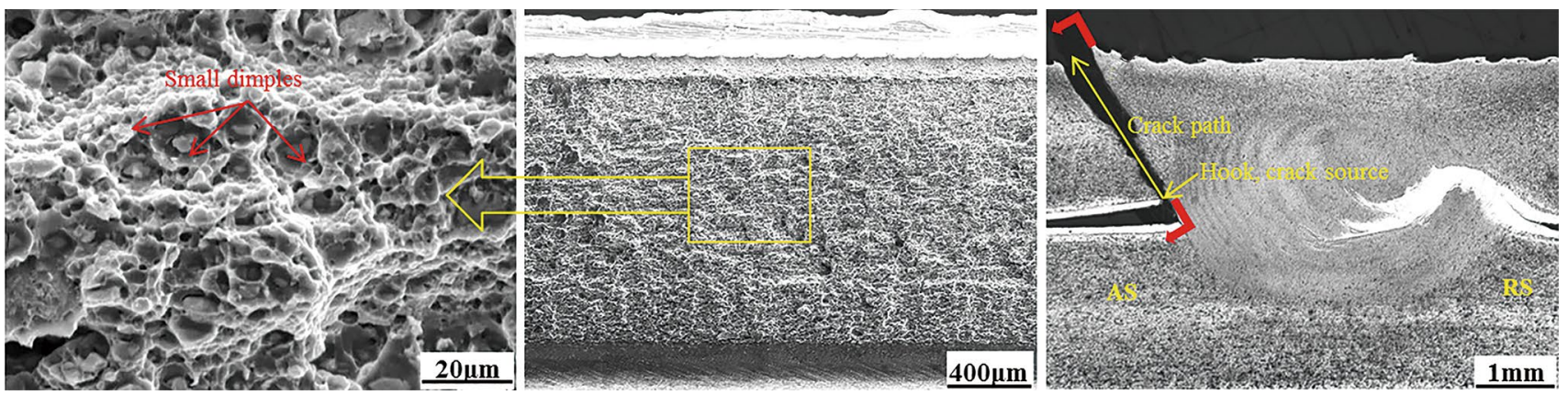

Fig. 10 Crack path and fracture morphology of the joint welded at a PLD of $2.55 \mathrm{~mm}$

and mechanical properties of the lap joints was studied. The following conclusions were drawn.

(1) The PLD fluctuation in submillimeters causes significant variation in the axial force. When the PLD is set to approximately $2.55 \mathrm{~mm}$ with a fluctuation of $0.1 \mathrm{~mm}$, i.e., varies by $4 \%$, the corresponding axial force varies by $70 \%$.

(2) The PLD fluctuation in submillimeters affects the voids (i.e., Void I and Void II), hook, and EST, among which the effects of Void II and the hook height could be negligible, and Void I turns to be the main factor that affects the EST. The EST increases along with the PLD corresponding to the shrinkage of Void I, which vanishes finally when the PLD is increased to and over $2.50 \mathrm{~mm}$.

(3) The tensile shear testing shows that the fracture load of the joint increases along with the PLD first and then decreases slightly, and this follows the rule of the ESTPLD function and axial force-PLD function. There is an optimized PLD at approximately $2.55 \mathrm{~mm}$, at which the EST reaches $1.71 \mathrm{~mm}$, corresponding to a peak fracture load of $11.03 \mathrm{kN}$. A PLD of $2.55 \mathrm{~mm}$ is suggested, with a tolerance of $0.02 \mathrm{~mm}$, corresponding to a fracture load of $9.6-11.0 \mathrm{kN}$, i.e., within a fluctuation of $12 \%$.

(4) In tensile shear testing of the joints, the fracture morphology shows different fracture mechanisms dependent on Void I. For the joint with Void I formed, the crack initiates from the location of Void I and propagates up and down in two directions. However, for the joint without Void I, the crack initiates from the hook tip and propagates along a $45^{\circ}$ direction to the loading direction.

Acknowledgements The authors would like to thank Dr. Junmiao Shi for his guidance in the Introduction, Dr. Feng Jin for his logical proof, and Ms. Xujing Nan for her graphing assistance.

\section{References}

[1] Z.W. Li, Y.M. Yue, S.D. Ji, P. Chai, Z.L. Zhou, Mater. Des. 90, $244(2016)$

[2] Y.X. Huang, L. Wan, X.Q. Si, T.F. Huang, X.C. Meng, Y.M. Xie, Metall. Mater. Trans. A 50, 296 (2019)

[3] Y.X. Huang, L. Wan, X.C. Meng, Y.M. Xie, Z.L. Lv, L. Zhou, J. Manuf. Process. 35, 424 (2018)

[4] H.J. Liu, Y.Q. Zhao, Y.Y. Hu, S.X. Chen, Z. Lin, Int. J. Adv. Manuf. Technol. 78, 1416 (2015)

[5] N.Z. Khan, A.N. Siddiquee, Z.A. Khan, J. Alloys Compd. 648, 366 (2015)

[6] P. Upadhyay, A.P. Reynolds, Mater. Sci. Eng. A 558, 396 (2012)

[7] Y.G. Kim, H. Fujii, T. Tsumura, T. Komazaki, K. Nakata, Mater. Sci. Eng. A 415, 253 (2006)

[8] N.Z. Khan, A.N. Siddiquee, Z.A. Khan, Measurement 129, 112 (2018)

[9] M. Dehghani, A. Amadeh, S.A.A. Mousavi, Mater. Des. 49, 434 (2013)

[10] Z.H. Ge, S.S. Gao, S.D. Ji, D.J. Yan, Int. J. Adv. Manuf. Technol. 98, $1462(2018)$

[11] J.M. Tang, Y.H. Shen, Alloys Compd. 666, 498 (2016)

[12] S. Zhang, Q.Y. Shi, Q. Liu, R.S. Xie, G. Zhang, G.Q. Chen, Int. J. Heat Mass Transf. 125, 34 (2018)

[13] Y.M. Yue, Z.W. Li, S.D. Ji, J. Mater. Sci. Technol. 32, 671 (2016)

[14] S.K. Zou, S.Y. Ma, C.M. Liu, C. Chen, L.M. Ma, J.P. Lu, J. Guo, Metals 7, 1 (2017)

[15] S.B. Aziz, M.W. Dewan, D.J. Huggett, M.A. Wahab, A.M. Okeil, T.W. Liao, Acta Metall. Sin. (Engl. Lett.) 29, 871 (2016)

[16] H.Y. Chen, F. Li, L. Pei, F.J. Liu, Mater. Charact. 125, 163 (2017)

[17] G.Q. Wang, Y.H. Zhao, Y.F. Hao, J. Mater. Sci. Techol. 34, 73 (2018)

[18] G.K. Padhy, C.S. Wu, S. Gao, J. Mater. Sci. Techol. 34, 2 (2018)

[19] J. Zhang, X.S. Feng, J.S. Gao, H. Huang, Z.Q. Ma, L.J. Guo, J. Mater. Sci. Techol. 34, 225 (2018)

[20] B.T. Gibson, D.H. Lammlein, T.J. Prater, W.R. Longhurst, C.D. Cox, M.C. Ballun, K.J. Dharmaraj, G.E. Cook, A.M. Strauss, J. Manuf. Process. 16, 64 (2014)

[21] S. Zhao, Q.Z. Bi, Y.H. Wang, Int. J. Adv. Manuf. Technol. 85, 2628 (2016)

[22] A. Fehrenbacher, C.B. Smith, N.A. Duffie, N.J. Ferrier, F.E. Pfefferkorn, M.R. Zinn, J. Manuf. Sci. Eng. 136, 021007 (2014)

[23] J.G. Ren, L. Wang, D.K. Xu, L.Y. Xie, Z.C. Zhang, Acta. Metall. Sin. (Engl. Lett.) 30, 230 (2017)

[24] Y.C. Lin, Y.C. Xia, Y.Q. Jiang, H.M. Zhou, L.T. Li, Mater. Sci. Eng. A 565, 420 (2013) 